\title{
Gender differences in self reported long term outcomes following moderate to severe traumatic brain injury
}

\author{
Angela Colantonio ${ }^{1,2^{*}+}$, Jocelyn E Harris ${ }^{1 \dagger}$, Graham Ratcliff ${ }^{3}$, Susan Chase $^{4}$, Kristina Ellis ${ }^{2}$
}

\begin{abstract}
Background: The majority of research on health outcomes after a traumatic brain injury is focused on male participants. Information examining gender differences in health outcomes post traumatic brain injury is limited. The purpose of this study was to investigate gender differences in symptoms reported after a traumatic brain injury and to examine the degree to which these symptoms are problematic in daily functioning.

Methods: This is a secondary data analysis of a retrospective cohort study of 306 individuals who sustained a moderate to severe traumatic brain injury 8 to 24 years ago. Data were collected using the Problem Checklist (PCL) from the Head Injury Family Interview (HIFI). Using Bonferroni correction, group differences between women and men were explored using Chi-square and Wilcoxon analysis.

Results: Chi-square analysis by gender revealed that significantly more men reported difficulty setting realistic goals and restlessness whereas significantly more women reported headaches, dizziness and loss of confidence. Wilcoxon analysis by gender revealed that men reported sensitivity to noise and sleep disturbances as significantly more problematic than women, whereas for women, lack of initiative and needing supervision were significantly more problematic in daily functioning.

Conclusion: This study provides insight into gender differences on outcomes after traumatic brain injury. There are significant differences between problems reported by men compared to women. This insight may facilitate health service planners and clinicians when developing programs for individuals with brain injury.
\end{abstract}

\section{Background}

According to the Center for Disease Control and Prevention, 1.7 million Americans sustain a traumatic brain injury (TBI) each year [1]. Advances in medical technology and care have led to increasing numbers of individuals surviving TBI and requiring ongoing community services to facilitate their return to everyday activities [2-4]. The majority of research to date is predominantly focused on male participants likely due to males having a higher incidence of TBI than women. Information regarding the effect of TBI on women's health is limited. Further, it is known that women with disability lack sufficient medical care compared to women without a disability [5]. The examination of health outcomes based

\footnotetext{
* Correspondence: angela.colantonio@utoronto.ca

† Contributed equally

${ }^{1}$ Toronto Rehabilitation Institute, 550 University Avenue, Toronto, Canada

Full list of author information is available at the end of the article
}

on gender may reflect important differences post TBI and help inform health service decision-makers.

There is a growing body of literature examining gender differences in outcome post TBI, however, findings are inconsistent. In a meta-analysis by Farace and Alves [6] women reported worse outcomes than men in $85 \%$ of measured variables; this was further supported in a recent systematic review [7] but with emphasis on worse outcomes in studies using older women. Conversely, others report superior results for community integration for women $[8,9]$. Further, studies investigating gender and its influence on functional outcome, found no difference between men and women [10-12]. Though similarities in functional outcome are apparent, consistent differences in TBI symptoms between men and women have been identified.

Literature examining gender differences in neuropsychological symptoms post TBI is more extensive than 
literature examining community integration and functional recovery. Numerous studies of gender differences in cognitive and psychological test performance have illustrated important distinctions. Executive function has been found to be superior in women compared to men post TBI [13-15] as well as memory and cognitive flexibility [16-18]. Whiteneck et al [19] studied outcomes after hospitalization for TBI one-year post-injury. Women were more likely to report symptoms such as fatigue, headaches, and balance problems compared to men. Headaches have been reported more frequently by women than men post TBI in several studies [20-22]. Hibbard et al [21] examined the prevalence of health issues 10 years post TBI and found being female and increased age were significant predictors for thyroid conditions, sleep difficulties, loss of urinary control and arthritis. Further, gender differences in symptoms of depression and anxiety have been reported with women demonstrating consistently worse outcomes $[18,20,23]$. These results highlight continued difficulty with cognitive and emotional functioning long after injury and reflect the need for ongoing health service programs.

This study is part of a larger study which was designed to examine long term outcomes post TBI [24]. A study objective was to examine the impact of factors such as gender and injury severity on long term outcomes. This study examines gender differences on selfreported symptoms 7 to 24 years after a moderate to severe traumatic brain injury and examines gender differences in the degree to which reported symptoms present as a problem for daily functioning.

\section{Methods \\ Participants}

Participants were from a retrospective cohort study on long term function post TBI [24]. Participants $(\mathrm{n}=306)$ had sustained a moderate to severe TBI and were discharged from a rehabilitation treatment centre in Pittsburgh, Pennsylvania. The criteria for inclusion were: (1) participants sustained the TBI at age 14 or older; (2) participants had specific head injury ICD-8 and ICD-9 codes (800-801.9, 803-804.9, 850-854.9: concussion; cerebral laceration or contusion; subarachnoid, subdural, or extra-dural hemorrhage or injury; and fractures to the skull); (3) participants lived within a 150 mile radius from the HealthSouth Harmarville Rehabilitation Hospital in Pennsylvania. Ethics approval was granted from the research ethics boards at the University of Toronto and the Healthsouth Rehabilitation Hospital.

\section{Data collection procedure}

The data collection procedure is described in detail in the original study. Essentially 642 individuals identified through medical record review were eligible for an interview, but 42 were not traceable, 128 were deceased, and 82 had moved. The remaining 390 eligible individuals were sent a letter introducing the study and requesting their participation. If the individual did not wish to be contacted, they were to call the project office's confidential phone line. Seven days later a trained interviewer phoned these individuals to arrange for a home interview, at which time informed consent was obtained. Among the 390 persons eligible for an interview, 30 were lost to follow up and 52 refused. Interviews were scheduled for 308 individuals. Physical, cognitive or communication limitations prevented 22 individuals from participating in the interview. In 20 of these cases, the individual nominated a caregiver/friend/ family member to complete the interview. The data used in this study was collected from interviews with 286 survivors and 20 informants.

\section{Assessments}

Information relating to demographics (e.g. age, martial status, and level of education) and injury characteristics (e.g. time since, cause, and severity) was taken from medical records and the History and Physical Medicine and Rehabilitation Evaluation, conducted by the admitting physicians in the rehabilitation hospital. In older records the Glasgow Coma Scale was inconsistently completed. To be consistent, information about length of unconsciousness or post-traumatic amnesia (PTA) was used to establish injury severity. Estimates of the durations of coma and PTA were derived from the admitting physician's account of the acute care phase.

The instrument used to collect the data was the Problem Checklist (PCL) from the Head Injury Family Interview (HIFI) [25]. The PCL is a two-part, self-report measure of 43 symptoms that are commonly experienced after a brain injury. In part A, participants answer 'yes' or 'no' to whether they currently experience one of the symptoms such as headaches, irritability, or forgetfulness. If the participant endorses the symptom in part $\mathrm{A}$, they are then asked to rate 'how much of a problem this symptom presents in their daily functioning' (part B). Rating is done using a seven point Likert scale with one indicating 'no problem' to seven indicating 'severe problem'. Good internal validity (Cronbach's $\alpha=0.91$ to 0.78 ) and construct validity ( $r=0.46$ to 0.37 ) were found [25]. Because the PCL is self-report, Kay and colleagues [25] compared reports from individuals with TBI to those obtained from family members in order to validate responses; they found significant correlations $(\mathrm{p}<0.001)$ for all scales. Paniak et al [26] found the PCL was sensitive to differences in symptom reporting between individuals with TBI and those without $(\mathrm{p}<0.001)$. 


\section{Analyses}

Descriptive statistics were generated, such as frequency distributions, measures of central tendencies and dispersion by gender. Group differences defined by gender were produced using Chi-square for dichotomous variables and Wilcoxon two-tailed test for continuous data from Part B of the PCL. We completed analysis for multiple comparisons using Bonferonni's adjustment with correction for correlation between observations [27,28]. Significance for adjusted differences was set at $\mathrm{p} \leq 0.025$. Calculations were performed using SAS statistical software package.

\section{Results}

\section{Sociodemographic information}

Of the 306 participants, there were 213 men and 93 women. No significant differences were found between men and women for demographic and injury-related characteristics, which are displayed in Table 1 . The mean age at injury was 29 for men and 32 for women and the mean age at follow-up was 43 years for men and 46 years for women. Men and women both had a mean of 14 years from time of injury to follow-up, with the range being 8-24 years for men and 7-24 years for women. Both men and women had a mean of 12 years of education prior to injury. Data on loss of consciousness (LOC) were available for most participants (182 men and 76 women). LOC for greater than 24 hours was noted for $76 \%$ of men and $70 \%$ of women. LOC for greater than one week was found in $49 \%$ of men and $47 \%$ of women. Individuals with a LOC of less than one hour included $13 \%$ of men and $17 \%$ of women.

\section{Gender differences on symptoms reported - Part A of the PCL}

Women reported being forgetful (70.1\%), difficulty remembering the right word $(63.6 \%)$, poor balance

Table 1 Demographic and injury characteristics $($ Men $=213$, Women $=93)$

\begin{tabular}{|c|c|c|c|c|}
\hline \multirow[t]{2}{*}{ Characteristics } & \multicolumn{2}{|c|}{$\mathbf{N}$} & \multicolumn{2}{|c|}{$\mathbf{N}$} \\
\hline & $M(S D)$ & W(SD) & $M(\%)$ & W(\%) \\
\hline Age at injury & $29(12)$ & $32(15)$ & & \\
\hline Current age & $43(12)$ & $46(15)$ & & \\
\hline Years since injury & $14(4.3)$ & $14(4.6)$ & & \\
\hline Year of education prior to injury & $12(1.9)$ & $12(2.5)$ & & \\
\hline \multicolumn{5}{|l|}{ Marital Status at injury } \\
\hline - Married & & & $73(34)$ & $34(37)$ \\
\hline - Not married & & & $124(58)$ & $45(49)$ \\
\hline - Separated/divorced/widowed & & & $15(7)$ & $12(13)$ \\
\hline \multicolumn{5}{|l|}{ Loss of consciousness } \\
\hline - Less than 1 hour & & & $24(13)$ & $13(17)$ \\
\hline - Greater than 1 day & & & $138(76)$ & $53(70)$ \\
\hline - Greater than 1 week & & & $89(49)$ & $36(47)$ \\
\hline
\end{tabular}

(62.5\%), visual problems (57.9\%) and irritability (57.4\%) most frequently. Similar findings were found for men with forgetfulness $(72.6 \%)$, irritability $(66.1 \%)$, poor balance $(65 \%)$, doing things slowly $(62.5 \%)$ and difficulty remembering the right word $(58.7 \%)$ reported most frequently. A summary of gender differences on self reported symptoms in part A of the PCL can be found in Table 2. Significantly more men than women reported difficulty setting realistic goals $(\mathrm{p}<0.02)$, high sex drive and restlessness $(\mathrm{p}<0.01)$, whereas significantly more women than men reported loss of confidence $(\mathrm{p}<0.02)$ as a problem.

\section{Table 2 Chi-Square Gender Differences on the Problem Checklist for Symptoms Reported With Over 30\% Frequency - Part A of Checklist}

\begin{tabular}{|c|c|c|c|}
\hline Symptom & Male - \% Yes & Female - \% Yes & P-Value* \\
\hline 1a Visual & 51.2 & 57.9 & 0.29 \\
\hline 3a Balance & 65.0 & 62.5 & 0.67 \\
\hline $4 a$ Slow & 62.5 & 53.4 & 0.14 \\
\hline $5 \mathrm{a}$ Words & 43.3 & 34.4 & 0.15 \\
\hline 6a Coordination & 56.1 & 50.5 & 0.38 \\
\hline 7a Tired & 44.8 & 49.4 & 0.47 \\
\hline 8a Headaches & 29.6 & 42.5 & 0.03 \\
\hline 9a Dizziness & 19.1 & 30.5 & 0.03 \\
\hline 13a Word finding & 58.7 & 63.6 & 0.43 \\
\hline 14a Wordy & 38.8 & 44.3 & 0.37 \\
\hline 15a Distracted & 44.7 & 39.7 & 0.42 \\
\hline 16a Concentration & 47.2 & 40.9 & 0.31 \\
\hline 17a Forgetful & 72.6 & 70.1 & 0.66 \\
\hline 18a Think clearly & 37.3 & 37.6 & 0.95 \\
\hline 19a Planning & 30.5 & 33.3 & 0.63 \\
\hline 20a Set Goals & 37.3 & 23.2 & 0.02 \\
\hline 21a Finishing & 33.3 & 32.1 & 0.84 \\
\hline 22a Apathy & 42.0 & 38.6 & 0.58 \\
\hline 23a Initiative & 38.6 & 30.6 & 0.19 \\
\hline 24a Irritability & 66.1 & 57.4 & 0.15 \\
\hline 25a Restlessness & 52.9 & 37.0 & 0.01 \\
\hline 26a Temper & 51.4 & 52.8 & 0.83 \\
\hline 27a Mood Swings & 37.7 & 44.9 & 0.24 \\
\hline 31a Bored & 45.7 & 38.3 & 0.24 \\
\hline 32a Complain & 33.6 & 36.0 & 0.69 \\
\hline 33a Dependent & 46.6 & 40.2 & 0.31 \\
\hline 35a Anxiety & 48.0 & 52.8 & 0.44 \\
\hline 36a Depression & 47.2 & 48.8 & 0.80 \\
\hline 37a Lonely & 38.3 & 30.2 & 0.19 \\
\hline 38a Confidence & 37.5 & 50.0 & 0.02 \\
\hline 42a High sex drive & 21.39 & 09.52 & 0.01 \\
\hline 43a Personality & 32.1 & 40.0 & 0.20 \\
\hline
\end{tabular}

*adjusted $p$ value $=0.02$ 


\section{Gender differences in problematic symptoms - Part B of the PCL}

A summary of gender differences on the mean scores from part B of the PCL can be found in Table 3. For men, the five most frequently reported problems were loss of confidence, sleep difficulty, difficulty thinking clearly, needing supervision, and fatigue. For women, needing supervision, lack of initiative, difficulty planning and organizing things, difficulty thinking clearly, and difficulty setting realistic goals were the most frequently reported problems. Men reported sensitivity to noise $(\mathrm{p}<0.02)$ and sleep disturbances $(\mathrm{p}<0.02)$ as having a greater impact on daily functioning compared to women. Symptoms presenting significantly more of a problem in daily functioning for women compared to men was lack of initiative $(\mathrm{p}<0.02)$ and needing supervision $(\mathrm{p}<0.02)$.

\section{Discussion}

This is the only study to our knowledge that has investigated gender differences on self reported symptoms and symptom impact on daily living many years post injury. We found several similarities on self reported symptoms between men and women but also significant differences. These differences can provide information to health care providers for the planning and delivery of care for individuals with a TBI.

Four of the five most reported symptoms were the same for men and women, highlighting similarities in symptoms experienced after TBI. These symptoms include being forgetful, irritability, poor balance, and word finding difficulties. This finding is consistent with previous studies of symptom prevalence [19,22,29]. Poor balance was the third most reported symptom for men and women after TBI which has safety implications, particularly since the main cause of brain injury in older adults is falls [2]. The diversity of self-reported symptoms reported in the chronic stage of recovery indicates the need for ongoing services to provide programming which includes cognitive, physical, psychosocial components in order to facilitate successful integration into community life.

Significantly more women reported headaches and dizziness than men. This difference is supported by previous studies with TBI survivors $[19,21,22]$ as well as in the general population [30,31]. Therefore, the distinction found in our study may not be directly related to the injury, but rather reflect what is found in the general population. Why women comprise a larger proportion of individuals reporting these symptoms is not clear, although there is some evidence of neurophysiological factors [21,32].

Additionally, headaches can be attributed to soft tissue injury of the neck and upper body; women may be
Table 3 Wilcoxon Gender Differences on the Problem Checklist for Symptom Impact on Daily Function Part B of Checklist

\begin{tabular}{|c|c|c|c|}
\hline Symptom & Mean: Male & Mean: Female & p-value* \\
\hline 2b Hearing & 3.3 & 2.4 & 0.01 \\
\hline 3b Balance & 3.8 & 3.7 & 0.64 \\
\hline 4b Slow & 3.5 & 3.8 & 0.44 \\
\hline 5b Words & 3.6 & 3.3 & 0.43 \\
\hline 6b Coordination & 4.0 & 4.0 & 0.85 \\
\hline 7b Tired & 4.0 & 3.5 & 0.21 \\
\hline 8b Headaches & 3.4 & 3.1 & 0.48 \\
\hline 9b Dizziness & 3.4 & 3.1 & 0.58 \\
\hline 10b Noise & 3.5 & 2.6 & 0.02 \\
\hline 11b Light & 3.8 & 3.1 & 0.23 \\
\hline 13b Word finding & 3.6 & 3.44 & 0.37 \\
\hline 14b Wordy & 3.9 & 3.6 & 0.38 \\
\hline 15b Distracted & 3.5 & 4.0 & 0.19 \\
\hline 16b Concentration & 4.0 & 3.8 & 0.69 \\
\hline $17 \mathrm{~b}$ Forgetful & 3.9 & 3.7 & 0.44 \\
\hline 18b Think clearly & 4.1 & 4.1 & 0.93 \\
\hline 19b Planning & 3.9 & 4.2 & 0.45 \\
\hline 20b Set Goals & 3.8 & 4.1 & 0.54 \\
\hline 21b Finishing & 3.9 & 4.1 & 0.78 \\
\hline 22b Apathy & 3.4 & 4.0 & 0.11 \\
\hline 23b Initiative & 3.7 & 4.5 & 0.02 \\
\hline 24b Irritability & 3.3 & 3.3 & 0.87 \\
\hline 25b Restlessness & 3.6 & 3.5 & 0.85 \\
\hline 26b Temper & 3.4 & 3.6 & 0.47 \\
\hline 27b Mood Swings & 3.9 & 3.5 & 0.35 \\
\hline 28b Emotional & 3.6 & 3.7 & 0.78 \\
\hline 30b Violent & 3.5 & 3.4 & 1.00 \\
\hline $31 b$ Bored & 3.8 & 3.7 & 0.74 \\
\hline 32b Complain & 3.4 & 3.2 & 0.68 \\
\hline 33b Dependent & 3.7 & 4.0 & 0.51 \\
\hline 34b Supervision & 4.0 & 5.5 & 0.02 \\
\hline 35b Anxiety & 3.1 & 3.4 & 0.24 \\
\hline 36b Depression & 3.6 & 3.5 & 0.93 \\
\hline 37b Lonely & 3.7 & 3.8 & 0.70 \\
\hline 38b Confidence & 4.3 & 3.9 & 0.33 \\
\hline 40b Sleep & 4.2 & 3.1 & 0.02 \\
\hline 41b Low sex drive & 3.7 & 3.1 & 0.37 \\
\hline 42b High sex drive & 2.2 & 3.5 & 0.01 \\
\hline 43b Personality & 3.1 & 3.2 & 0.78 \\
\hline
\end{tabular}

*adjusted $p$ value $=0.025$

more susceptible to trauma of soft tissue during acceleration-deceleration injuries due to higher head to body mass ratio compared to men [33]. Regardless, headaches and dizziness are associated with difficulty performing daily activities $[19,34,35]$ and vocational tasks [36,37]. 
As such, these symptoms should be a priority for treatment intervention, pharmacological and educational, along the continuum of care.

Men reported hearing/noise difficulties and sleep disturbances as significantly more problematic than women. Several studies have found sensitivity to noise as a prominent sequelae of TBI $[20,22,38]$ and a factor in poor functional outcome $[19,20,39]$. The meta-analysis by Farace and Alves [6] found significantly more men than women reported hearing related problems. Noise sensitivity may impact social and vocational involvement and success, known areas of difficulty post TBI $[3,19,40]$. Clinicians may need to incorporate environmental assessments into discharge and return to work planning to detect possible noise/hearing irritants that could impact effective community integration.

Sleep disturbances are prevalent in both men and women post TBI [41-43] and can complicate recovery $[44,45]$. Sleep disturbances are also associated with depression, anxiety, and poor outcome on cognitive measures $[44,46,47]$. Self-report of sleep disturbances makes it difficult to determine whether the issue relates to the TBI itself or to secondary complications such as depression, stress or pain [48-50]. In our study men reported sleep disturbances as significantly more problematic for daily living compared to women. One explanation may be the effect of sleep deprivation on paid work as more men in our study were working outside the home than women. The literature is inconclusive regarding gender differences and subsequent causes of sleep disturbances $[41,44]$. Vigilance to the pervasive impact of sleep disturbances for individuals with TBI is imperative. The complex interrelationship between TBI, cognitive and psychological symptoms and sleep disturbances further supports the need for comprehensive assessment and treatment programs.

Self-report measures such as the one used in this study can capture the socio-medical perspective of health such as social influence on illness and health reporting behaviours, which may account for some of our results [51]. The fact that significantly more men reported high sex drive than women may be due to social acceptance and willingness to report rather than an organic brain disturbance caused by the injury. In addition, women reported needing supervision as significantly more problematic than men. Again, this may reflect the social pressure of sustaining care-taker and home-maker roles without feeling able to ask for assistance. Additionally, environmental constraints may affect a woman's ability to perform and balance home and community activities, thus the need for assistance [5].

\section{Limitations}

A main limitation of this study is the lack of a control group to ensure symptoms reported are due to the TBI and not a reflection of differences seen in the general population. In addition, due to the many comparisons in our study, it is possible that some of our significant differences are spurious; however we did use an adjusted $p$ value to minimize type 1 error. Further, one participant's interpretation of a symptom, such as 'thinking clearly' may be different from another's, which could influence the frequency and magnitude of symptom reporting. Selfreport measures may not reflect true symptomology as measured by standardized neuro-cognitive tests; however, our goal was to document reported symptoms and their effect on daily functioning rather than measure cognitive deficits. Our participants were a minimum of seven years post injury, however the PCL was developed using a sample of individuals three years post injury; there may be differences in symptoms and symptom impact when measured at later stages of chronicity. Since some of our participants were classified with milder injury, findings may not accurately represent this sub-population.

\section{Conclusion}

In conclusion, men and women experience symptoms that are problematic many years after a TBI. We found similarities and differences in reported symptoms based on gender. Future research examining gender differences in how cognitive and physical symptoms influence community integration and performance in day to day activities would contribute to the understanding of the dynamic interaction between these concepts. Since some of our participants were classified with milder injury, findings may not accurately represent this sub-population.

\section{Acknowledgements}

Funding for this study was obtained from NINDS (NS34740-2), NIA (F33 AGO5856-01A1), Washington County Brain Injury Association, the Canadian Institutes for Health Research and the Toronto Rehabilitation Institute. Support for this study was given to JEH in a CIHR Fellowship Award and a Strategic Training Fellowship in Health Care, Technology and Place (FRN: STP 53911).

\section{Author details}

${ }^{1}$ Toronto Rehabilitation Institute, 550 University Avenue, Toronto, Canada. ${ }^{2}$ Department of Occupational Science and Occupational Therapy, University of Toronto, 500 University Avenue, Toronto, Canada. ${ }^{3}$ HealthSouth, Harmarville Rehabilitation Center, 320 Guys Road, PA, US. ${ }^{4}$ Working Order 1650 Main Street, Sharpsburg, PA, US.

\section{Authors' contributions}

AC was responsible for the concept, design, coordination of the study as well as data analysis/interpretation and manuscript revisions.

JEH was responsible for data analysis and interpretation as well as the writing and revisions of this manuscript.

GR was responsible for the concept, design, and coordination of the study and manuscript approval.

SC was responsible for the concept, design, and coordination of the study as well as manuscript approval.

KE was responsible for preliminary data analysis and interpretation and manuscript approval. 


\section{Competing interests}

The authors declare that they have no competing interests.

Received: 7 May 2010 Accepted: 28 October 2010

Published: 28 October 2010

\section{References}

1. Faul M, Xu L, Wald MM, Coronado VG: Traumatic Brain Injury in the United States: Emergency Department Visits, Hospitalizations and Deaths 2002-2006 2010.

2. Colantonio A, Croxford R, Farooq S, Laporte A, Coyte PC: Trends in hospitalization associated with traumatic brain injury in a publicly insured population, 1992-2002. J Trauma 2009, 66(1):179-183.

3. Corrigan JD, Selassie AW, Orman JA: The epidemiology of traumatic brain injury. J Head Trauma Rehabil 2010, 25(2):72-80.

4. Myburgh JA, Cooper DJ, Finfer SR, Venkatesh B, Jones D, Higgins A, Bishop N, Higlett T, Australasian Traumatic Brain Injury Study (ATBIS) Investigators for the Australian, New Zealand Intensive Care Society Clinical Trials Group: Epidemiology and 12-month outcomes from traumatic brain injury in australia and new zealand. J Trauma 2008, 64(4):854-862.

5. Tate DG, Roller S, Riley B: Quality of life for women with physical disabilities. Phys Med Rehabil Clin N Am 2001, 12(1):23-37.

6. Farace $E$, Alves WM: Do women fare worse: a metaanalysis of gender differences in traumatic brain injury outcome. J Neurosurg 2000, 93(4):539-545.

7. Slewa-Younan S, van den Berg S, Baguley IJ, Nott M, Cameron ID: Towards an understanding of sex differences in functional outcome following moderate to severe traumatic brain injury: a systematic review. J Neurol Neurosurg Psychiatry 2008, 79(11):1197-1201.

8. Doninger NA, Heinemann AW, Bode RK, Sokol K, Corrigan JD: Predicting community integration following traumatic brain injury with health and cognitive status measures. Rehabil Psych 2003, 48:67.

9. Reid-Arndt SA, Nehl C, Hinkebein J: The Frontal Systems Behaviour Scale (FrSBe) as a predictor of community integration following a traumatic brain injury. Brain Inj 2007, 21(13-14):1361-1369.

10. Mushkudiani NA, Engel DC, Steyerberg EW, Butcher I, Lu J, Marmarou A, Slieker F, McHugh GS, Murray GD, Maas Al: Prognostic value of demographic characteristics in traumatic brain injury: results from the IMPACT study. J Neurotrauma 2007, 24(2):259-269.

11. Ponsford JL, Myles PS, Cooper DJ, Mcdermott FT, Murray LJ, Laidlaw J, Cooper G, Tremayne AB, Bernard SA: Gender differences in outcome in patients with hypotension and severe traumatic brain injury. Injury 2008, 39(1):67-76.

12. Green AM, Baguley IJ, Gurka JA, Marosszeky JE: Sex differences in injury severity and outcome measures after traumatic brain injury. Arch Phys Med Rehabil 2004, 85:376-379.

13. Barr WB: Neuropsychological testing of high school athletes. Preliminary norms and test-retest indices. Arch Clin Neuropsychol 2003, 18(1):91-101.

14. Niemeier JP, Marwitz JH, Lesher K, Walker WC, Bushnik T: Gender differences in executive functions following traumatic brain injury. Neuropsychol Rehabil 2007, 17(3):293-313.

15. Putukian M, Echemendia RJ, Mackin S: The acute neuropsychological effects of heading in soccer: a pilot study. Clin I Sport Med 2000, 10(2):104-109.

16. Himanen $L$, Portin $\mathrm{R}$, Isoniemi $\mathrm{H}$, Helenius $\mathrm{H}$, Kurki T, Tenovuo O: Longitudinal cognitive changes in traumatic brain injury: a 30-year follow-up study. Neurology 2006, 66(2):187-192.

17. Ratcliff JJ, Greenspan Al, Goldstein FC, Stringer AY, Bushnik T, Hammond FM, Novack TA, Whyte J, Wright DW: Gender and traumatic brain injury: do the sexes fare differently? Brain Inj 2007, 21(10):1023-1030.

18. Schopp L, Shigaki C, Johnstone B, Kirlpatrick H: Gender differences in cognitive and emotional adjustment to traumatic brain injury. J Clin Psych Med Setting 2001, 8:181.

19. Whiteneck G, Brooks CA, Mellick D, Harrison-Felix C, Terrill MS, Noble K: Population-based estimates of outcomes after hospitalization for traumatic brain injury in Colorado. Arch Phys Med Rehabil 2004, 85(4 Suppl 2):S73-81.

20. Dischinger $P C$, Ryb GE, Kufera JA, Auman KM: Early predictors of postconcussive syndrome in a population of trauma patients with mild traumatic brain injury. J Trauma 2009, 66(2):289-96, discussion 296-7.
21. Hibbard MR, Uysal S, Sliwinski M, Gordon WA: Undiagnosed health issues in individuals with traumatic brain injury living in the community. J Head Trauma Rehabil 1998, 13(4):47-57.

22. Kraus J, Hsu P, Schaffer K, Vaca F, Ayers K, Kennedy F, Afifi AA: Preinjury factors and 3-month outcomes following emergency department diagnosis of mild traumatic brain injury. J Head Trauma Rehabil 2009, 24(5):344-354.

23. Bay E, Sikorskii A, Saint-Arnault D: Sex differences in depressive symptoms and their correlates after mild-to-moderate traumatic brain injury. J Neurosci Nurs 2009, 41(6):298-309, quiz 310-1.

24. Colantonio A, Ratcliff G, Chase S, Kelsey S, Escobar M, Vernich L: Long-term outcomes after moderate to severe traumatic brain injury. Disabil Rehabil 2004, 26(5):253-261.

25. Kay $\mathrm{T}$, Cavallo M, Ezrachi $\mathrm{O}$, Vavagiakis $\mathrm{P}$ : The head injury family interview: A clinical and research tool. J Head Trauma Rehabil 1995, 10:12.

26. Paniak C, Phillips K, Toller-Lobe G, Durand A, Nagy J: Sensitivity of three recent questionnaires to mild traumatic brain injury-related effects. J Head Trauma Rehabil 1999, 14(3):211-219.

27. Pavur R: Type I error rates for multiple comparison procedures with dependent data. The Am Statistician 1988, 42:171-173.

28. Sankoh AJ, Huque MF, Dubey SD: Some comments on frequently used multiple endpoint adjustment methods in clinical trials. Statistic Med 1997, 16:2529-2542.

29. Tennant A, Macdermott N, Neary D: The long-term outcome of head injury: implications for service planning. Brain Inj 1995, 9(6):595-60.

30. Langely RL: Sex and gender differences in health and disease. North Carolina, Carolina: Academic Press; 2003.

31. Macintyre S, Hunt K, Sweeting H: Gender differences in health: are things really as simple as they seem? Soc Sci Med 1996, 42(4):617-624.

32. Rees PM: Contemporary issues in mild traumatic brain injury. Arch Phys Med Rehabil 2003, 84(12):1885-1894.

33. Bell KR, Pepping M: Women and traumatic brain injury. Phys Med Rehabil Clin N Am 2001, 12(1):169-182.

34. Asikainen I, Kaste M, Sarna S: Predicting late outcome for patients with traumatic brain injury referred to a rehabilitation programme: a study of 508 Finnish patients 5 years or more after injury. Brain Inj 1998, 12(2):95-107.

35. McCauley SR, Boake C, Levin HS, Contant CF, Song JX: Postconcussional disorder following mild to moderate traumatic brain injury: anxiety, depression, and social support as risk factors and comorbidities. J Clin Exp Neuropsychol 2001, 23(6):792-808.

36. Ownsworth T, McKenna K: Investigation of factors related to employment outcome following traumatic brain injury: a critical review and conceptual model. Disabil Rehabil 2004, 26(13):765-783.

37. Ruffolo CF, Friedland JF, Dawson DR, Colantonio A, Lindsay PH: Mild traumatic brain injury from motor vehicle accidents: factors associated with return to work. Arch Phys Med Rehabil 1999, 80(4):392-398.

38. Attias J, Zwecker-Lazar I, Nageris B, Keren O, Groswasser Z: Dysfunction of the auditory efferent system in patients with traumatic brain injuries with tinnitus and hyperacusis. J Basic Clin Physiol Pharmacol 2005, 16(23):117-126.

39. Bohnen N, Twijnstra A, Jolles J: Post-traumatic and emotional symptoms in different subgroups of patients with mild head injury. Brain Inj 1992, 6(6):481-487.

40. Whelan-Goodinson R, Ponsford J, Schonberger M: Association between psychiatric state and outcome following traumatic brain injury. J Rehabil Med 2008, 40(10):850-857.

41. Baumann CR, Werth E, Stocker R, Ludwig S, Bassetti CL: Sleep-wake disturbances 6 months after traumatic brain injury: a prospective study. Brain 2007, 130(Pt 7):1873-1883.

42. Parcell DL, Ponsford JL, Rajaratnam SM, Redman JR: Self-reported changes to nighttime sleep after traumatic brain injury. Arch Phys Med Rehabil 2006, 87(2):278-285.

43. Zeitzer JM, Friedman L, O'Hara R: Insomnia in the context of traumatic brain injury. J Rehabil Res Dev 2009, 46(6):827-836.

44. Mahmood O, Rapport L, Hanks RA, Fichtenberg NL: Neuropsychological performance and sleep disturbance following traumatic brain injury. J Head Trauma Rehabil 2004, 19(5):378-390.

45. Worthington AD, Melia Y: Rehabilitation is compromised by arousal and sleep disorders: results of a survey of rehabilitation centres. Brain Inj 2006, 20(3):327-332. 
46. Bloomfield IL, Espie CA, Evans JJ: Do sleep difficulties exacerbate deficits in sustained attention following traumatic brain injury? I Int Neuropsychol Soc 2010, 16(1):17-25.

47. Orff HJ, Ayalon L, Drummond SP: Traumatic brain injury and sleep disturbance: a review of current research. J Head Trauma Rehabil 2009, 24(3):155-165.

48. Kim E, Lauterbach EC, Reeve A, Arciniegas DB, Coburn KL, Mendez MF, Rummans TA, Coffey EC, ANPA Committee on Research: Neuropsychiatric complications of traumatic brain injury: a critical review of the literature (a report by the ANPA Committee on Research). J Neuropsychiatry Clin Neurosci 2007, 19(2):106-127.

49. Moore EL, Terryberry-Spohr L, Hope DA: Mild traumatic brain injury and anxiety sequelae: a review of the literature. Brain Inj 2006, 20(2):117-132

50. Nampiaparampil DE: Prevalence of chronic pain after traumatic brain injury: a systematic review. JAMA 2008, 300(6):711-719.

51. Verbrugge LM: The twain meet: empirical explanations of sex differences in health and mortality. J Health Soc Behav 1989, 30(3):282-304.

\section{Pre-publication history}

The pre-publication history for this paper can be accessed here: http://www.biomedcentral.com/1471-2377/10/102/prepub

doi:10.1186/1471-2377-10-102

Cite this article as: Colantonio et al:: Gender differences in self reported long term outcomes following moderate to severe traumatic brain injury. BMC Neurology 2010 10:102.

\section{Submit your next manuscript to BioMed Central} and take full advantage of:

- Convenient online submission

- Thorough peer review

- No space constraints or color figure charges

- Immediate publication on acceptance

- Inclusion in PubMed, CAS, Scopus and Google Scholar

- Research which is freely available for redistribution

Submit your manuscript at www.biomedcentral.com/submit 